\title{
Metalenguaje y gramática de algunos juicios cotidianos de verdad en español
}

\author{
Metalanguage and Grammar of Some Everyday \\ Propositions about Truth in Spanish \\ Metalinguagem e gramática de alguns julgamentos \\ cotidianos de verdade em espanhol
}

Juan Antonio González de Requena Farré ${ }^{1}$

\section{Resumen}

Este artículo pretende ejemplificar los rendimientos metalingüísticos, metadiscursivos y metacomunicativos del lenguaje cotidiano, mediante una descripción gramatical de algunos juicios de verdad en español. Con ese propósito, se realiza un estudio comparativo de algunas expresiones cotidianas del tipo "La verdad es que $p$ ", "Es verdad que $p$ ", 0 bien "Esto/Eso es verdad"; específicamente, se analizan los tipos de cláusula relacional, los movimientos retóricos, el contenido de los juicios, la realización gramatical del término verdad y el ámbito de la posible negación. Al poner de manifiesto que el lenguaje natural dispone de recursos semióticos u opciones de significación para volverse reflexivamente sobre sí mismo, este trabajo cuestiona la pretensión de disponer de metalenguajes formalizados de orden superior.

\section{Palabras clave}

metalenguaje; metacomunicación; metadiscurso; juicios de verdad

\section{Abstract}

This paper seeks to exemplify the metalinguistic, metadiscursive and metacommunicative performances of everyday language through a grammatical description of some propositions about truth in Spanish. To that end, we carry out a comparative study of some everyday expressions like "The truth is that $p$ ", "It is true that $p$ ", or "This/That is true"; more specifically, we analyze the types of relational clause, the rhetorical movements, the content of the propositions, the grammatical realization of the term truth, and the scope of possible denial. By showing that natural language has semiotic resources or options of meaning to reflect about itself, this paper questions the desire to have formalized higher-order metalanguages.

\section{Keywords}

metalanguage; metacommunication; metadiscourse; propositions about truth

\section{Resumo}

Este artigo visa exemplificar os rendimentos metalinguísticos, metadiscursivos e metacomunicativos da linguagem cotidiana por meio de uma descrição gramatical de alguns julgamentos de verdade em espanhol. Com esse propósito, realiza-se um estudo comparativo de algumas expressões cotidianas do tipo "a verdade e p","é verdade que p", ou bem, "isto/isso é verdade"; especificamente, analisam-se os tipos de cláusula relacional, os movimentos retóricos, o conteúdo dos julgamentos, a realização gramatical do termo verdade e o âmbito da possível negação. Ao manifestar que a linguagem natural dispõe de recursos semióticos ou opções de significação para refletir sobre si mesma, este trabalho questiona a pretensão de dispor de metalinguagens formalizadas de ordem superior.

\section{Palavras-chave}

metalinguagem; metacomunicação; metadiscurso; julgamentos de verdade

Artículo recibido el 5 de abril de 2017 y aprobado el 10 de enero de 2018

1 Universidad Austral de Chile, correo electrónico: jgonzalez@spm.uach.cl 
Existe una paradójica relación con los metalenguajes en la misma ciencia del lenguaje que acuñó una gran parte de nuestra terminología metalingüística. Por una parte, la lingüística contemporánea ha forjado todo un repertorio de términos para designar la reflexividad del lenguaje, que hace posible hablar del propio lenguaje: metalenguaje, metasemiótica, metalengua, metahabla, metadiscurso, etc. En ocasiones, la noción de metalenguaje pretende aportar el plano de fundamentación que haría posible una ciencia del lenguaje, de manera que un lenguaje de orden superior pueda tener al lenguaje natural como lenguaje objeto (Hjemlslev, 1971; Tarski, 2005). Otras veces, la terminología metalingüística designa la reflexividad genérica del lenguaje, que puede hablar de cualquier elemento del lenguaje y referir el discurso ajeno, en la medida en que ningún aspecto de la experiencia humana resulta inefable, ni siquiera el propio lenguaje en que articulamos nuestra experiencia (Gutiérrez, 1989; Hernández, 1996; Lucy, 1993). También, se ha recurrido al léxico metalingüístico para referirse a aquellas funciones que enmarcan algunos usos cotidianos del lenguaje y hacen posible resolver las perturbaciones y malentendidos en la comunicación diaria (Jakobson, 1988; Vigara, 1992; Weinrich, 1981). O bien se ha invocado el metalenguaje para rescatar cierta conciencia lingüística del hablante respecto de su propio discurso, así como para patentizar determinada cultura lingüística implícitamente compartida que expresa idiomáticamente nuestro saber mundano sobre el lenguaje (González, 2006; Loureda, 2009). Asimismo, se ha recurrido a la noción de metadiscurso para poner en primer plano aquellos marcos pragmáticos de la enunciación, aquellas formas de posicionamiento discursivo $y$ aquellas formas de interacción de los interlocutores y los textos, que intervienen en la producción y recepción textuales (Hyland, 2005).

En todo caso, el concepto de metalenguaje no ha estado exento de cuestionamientos, en la medida en que no parece obvio que la ciencia del lenguaje pueda disponer de un lenguaje de orden superior formalmente desdoblado para referirse al lenguaje natural. Al fin y al cabo, las descripciones teóricas de la lengua cotidiana no pueden dejar de formularse en la gramática del propio lenguaje natural (Weinrich, 1981; Lyons, 1997), de manera que la relación entre metalenguaje y lenguaje objeto resulta tan fronteriza como paradójica (López, 1980). En fin, el panorama de la ciencia del lenguaje contemporánea revela un doble gesto paradójico de multiplicación de la terminología metalingüística y de cuestionamiento del metalenguaje.

Originariamente, el vocabulario del metalenguaje irrumpió en la discusión teórica vinculado a los problemas de definición de la verdad en un lenguaje formalizado de orden superior. En ese sentido, la concepción semántica de la verdad se centraba en la construcción de una definición satisfactoria de la noción de verdad, así como en la descripción de las reglas formales y la estructura del lenguaje formalizado en que se formula la definición del término (Tarski, 2005, pp. 67-70). La definición semántica de la verdad se asociaba así a una cláusula formal de equivalencia: $(V) X$ es verdadera si, y solo si, $p$. En esa formalización general de la noción de verdad, la $p$ puede ser reemplazada por cualquier oración empleada en el lenguaje, y la $X$ corresponde al nombre o mención de la oración representada por $p$ (Tarski, 2005, p. 79). El ejemplo característico mediante el cual Tarski insta la fórmula general de equivalencia que define la verdad resulta archiconocido: "La oración 'la nieve es blanca' es verdadera si, y solo si, la nieve es blanca" (Tarski, 2005, p. 96). Como se puede apreciar, el ejemplo concierne al contenido proposicional de una oración aislada, y responde básicamente a la exigencia formal de adecuación entre la mención de una expresión y la enunciación de un estado de cosas. Aunque se encuentran con cierta frecuencia en los textos de lógica y de semántica formal, el ejemplo metalingüístico ("La oración 'la nieve es blanca' es verdadera si, y solo si, la nieve es blanca") no constituiría una expresión que se realice cotidianamente en el lenguaje natural; más bien ejemplifica la necesidad de formalizar los enunciados de verdad en un metalenguaje, bajo la premisa de que el lenguaje natural carece de los recursos formales para estipular una definición precisa de la noción de 
verdad y de los juicios sobre la verdad. Ahora bien, los ejemplos que instan la definición semántica de la verdad resultan inteligibles en la medida en que cierta estructura lógico-semántica puede realizarse léxico-gramaticalmente en el lenguaje natural, aunque sea a través de una expresión que nadie formularía en una conversación o texto cotidianos (salvo en alguna asignatura de lógica o en los libros de semántica formal).

La definición semántica de la verdad parece constituir una formalización antinatural de los juicios de verdad en un presunto metalenguaje de orden superior, cuyas instancias, sin embargo, se realizan léxico-gramaticalmente con recursos de la lengua natural (aunque no se encuentren habitualmente en el lenguaje cotidiano). En la tradición filosófica, existen otras teorías de la verdad que no apelan a una formalización metalingüística de reglas de definición ni comparten el legado de la concepción de la verdad como adecuación lógica. Por ejemplo, las teorías coherentistas de la verdad se centran en la consistencia de conjunto de nuestros sistemas cognoscitivos; las teorías pragmatistas privilegian la eficacia instrumental respecto a la organización de nuestra experiencia y nuestra orientación en el mundo; las teorías fenomenológicas destacan la evidencia antepredicativa; o las perspectivas genealógicas consideran que la verdad es solo un dispositivo de control discursivo y exclusión de ciertas enunciaciones. También encontramos concepciones de la verdad que - en lugar de enrarecer el problema de la verdad como una cuestión lógica u ontológica - se preocupan por esclarecer la construcción discursiva de nuestros juicios de verdad. Por ejemplo, la concepción prooracional de la verdad lleva a cabo un análisis del significado lingüístico de las expresiones de la verdad y muestra que el término verdad nada añade al significado proposicional. Por otra parte, cierta concepción consensual de la verdad sostiene que la pretensión de validez constituye un presupuesto de toda comunicación, de modo que todo aquel que participa en el discurso argumentativo anticiparía implícitamente el reconocimiento intersubjetivo de las pretensiones de validez y el entendimiento consensual. Existen, pues, reconstrucciones del sentido de la verdad que parten de la gramática del lenguaje cotidiano y de los marcos pragmáticos de la comunicación discursiva (respecto a las teorías contemporáneas de la verdad, véase Nicolás y Frápolli, 1997).

En una perspectiva discursiva e intersubjetiva resulta pertinente preguntarse por las modalidades de realización léxico-gramatical de los juicios de verdad que se formulan efectivamente en el lenguaje cotidiano (y no solo en los textos de lógica o semántica formal). En efecto, los recursos semióticos u opciones de significación del lenguaje natural permiten expresar juicios de verdad sin necesidad de recurrir a un metalenguaje formalizado de orden superior. El sistema de significación del lenguaje natural no solo puede representar las relaciones lógicas de los contenidos proposicionales y las representaciones lingüísticas, sino que además expresa simultáneamente ciertas relaciones interpersonales entre los interlocutores, y significa determinados formatos de organización del mensaje textual (o sea, cumple funciones ideacionales, interpersonales y textuales, si adoptamos la terminología de la gramática sistémico funcional de Halliday y Matthiessen, 2004). Así, incluso el ejemplo metalingüístico ("La oración 'la nieve es blanca' es verdadera si, y solo si, la nieve es blanca") responde al potencial de significación del lenguaje natural. Por una parte, el ejemplo representa ideacionalmente ciertas relaciones lógico-semánticas de equivalencia entre oraciones, mediante una expansión hipotáctica condicional; asimismo, en la primera oración, se significa cierta relación lógica de identificación del contenido de verdad de la proposición que se representa en la cláusula incrustada, mediante el recurso gráfico de las comillas. Además, se da cierta organización textual de la información, de manera que la prótasis oracional aparece como información nueva, en tanto que la atribución de verdad a la oración mencionada constituye el tema dado (respecto a las definiciones asociadas a la organización informativa, véase Real Academia Española, 2010, pp. 753-754). Por otra parte, el ejemplo en cuestión expresa cierto significado interpersonal, por cuanto formula una declaración en modo indicativo y así contribuye 
a un virtual intercambio de información con los receptores, centrado en el contenido proposicional. Sin embargo, los recursos semióticos del sistema de la lengua natural que se emplean en el ejemplo metalingüístico resultan particularmente ajenos a los modos de significar juicios de verdad en los intercambios comunicativos cotidianos.

\section{Algunos juicios de verdad en el lenguaje natural}

En el lenguaje cotidiano encontramos expresiones de juicios de verdad que responden a las funciones interpersonales y textuales del lenguaje, de manera que no se limitan a representar ideacionalmente contenidos proposicionales, sino que además introducen posicionamientos y propuestas en el intercambio comunicativo, así como contribuyen a la organización de la información y a la cohesión de los elementos textuales. En el Corpus de Referencia del Español Actual (Real Academia Española, 2016b), encontramos ejemplos de expresiones de juicios de verdad como los siguientes:

(1) Las buenas personas piensan en el compositor como un ser milagroso que espera pacientemente la hora suprema del hallazgo ultraterreno. Eso es una hermosa creencia. Pero no corresponde a la verdad. La verdad es que el trabajo musical, como todos los trabajos, nace, crece y se reproduce con horario fijo. (Melo, citado por Real Academia Española, 2016b)

(2) Yo adelanté mi regreso en veinticuatro horas. Es verdad que había calculado mal al principio, sin contar con un día de fiesta en Suiza gracias al cual mis tareas terminaban el jueves y no el viernes de la semana octava. Pero de eso me di cuenta aquel lunes, y ese mismo día cambié el billete del sábado para el viernes. (Marías, citado por Real Academia Española, 2016b)

(3) El régimen alimenticio tiene un papel importante a desempeñar en el mantenimiento normal de la actividad sexual. Los impedimentos para la vida sexual normal son los excesos en la bebida y en la comida. Esto es verdad para la mujer y particularmente para los hombres de cierta edad. (Sintes, citado por Real Academia Española, 2016b).
Como se aprecia en los siguientes ejemplos, no resulta evidente que exista un juicio de verdad en algunos adverbios evidenciales (como verdaderamente) ni en aquellas locuciones que operan como marcadores discursivos (como, por ejemplo, los marcadores evidenciales como en verdad, a decir verdad o el marcador metadiscursivo de corroboración ¿verdad?):

(4) Julius del Piero no tuvo mucha suerte con la crítica. Los diarios y las revistas jamás se ocuparon de él. Y en Flores, los implacables Críticos de la calle Condarco lo atacaron siempre con ferocidad. En verdad, eran sujetos temibles. (Dolina, citado por Real Academia Española, 2016b)

(5) Todo lo presente, incluidos nosotros, estaba en, y era, al mismo tiempo, un lugar. A decir verdad, nosotros éramos, más que el lugar mismo, ese lugar, y como en ese anochecer parecía más acogedor, había algo de hiriente en su habitual mudez desdeñosa. (Saer, citado por Real Academia Española, 2016b)

(6) Me están pasando tantas cosas estos meses últimos, que me siento incapaz de resumirlas. Te he hablado ya de Gorostieta, ¿verdad? (Pombo, citado por Real Academia Española, 2016b)

(7) Por las indicaciones de un nativo hicímosnos una figuración de dónde podía ser hallado nuestro hipotético sanador. Verdaderamente, no sabíamos con precisión qué lugar era, pues los indígenas acostumbran a dar explicaciones en las que lo genérico es tratado de único y específico. (Arenales, citado por Real Academia Española, 2016b).

Aunque, en estos casos, parece reforzarse la aseveración realizada en un enunciado o solicitarse la corroboración conversacional (como pasa con ¿verdad?), no se formula una cláusula, realizada como juicio de verdad, que represente ideacionalmente la relación entre el valor de verdad y un contenido proposicional o una instancia de discurso determinados. (Respecto a los marcadores discursivos, véase Martín y Portolés, 1999; respecto a los adverbios evidenciales en castellano, véase Real Academia Española, 2010, pp. 594-595). 
Los tres primeros ejemplos sí que llevan a cabo un juicio de verdad sobre el contenido de una proposición o instancia discursiva, aunque difieren las maneras en que se realiza léxico-gramaticalmente la representación de cierta relación lógica, y existen distintas significaciones interpersonales y textuales de los enunciados en cuestión. En términos generales, se trata de cláusulas relacionales, que - como argumenta Halliday (Halliday y Matthiessen, 2004, pp. 210-214) - construyen la experiencia del mundo como una asociación o relación estática entre cosas o estados de cosas, y, para ello, recurren al presente de indicativo del verbo ser. Las cláusulas relacionales que expresan juicios de verdad podrían responder a alguna de las opciones de significación de relaciones abstractas: la clasificación (esto es, la adscripción o la inclusión en una clase), mediante una oración atributiva; o bien la identificación (o sea, la equivalencia reversible entre dos expresiones). Una cláusula atributiva puede expresar la relación entre una entidad portadora y un atributo o cualidad; por su parte, una cláusula de identidad establece una relación entre una instancia y un valor, o bien entre dos elementos identificados. A diferencia de las cláusulas de identidad, los términos de las cláusulas atributivas no son reversibles ("La afirmación de Pedro es verdad" no se puede convertir simplemente en " ${ }^{*}$ Verdad es la afirmación de Pedro"). Además, las cláusulas atributivas incorporan normalmente un grupo nominal indefinido como atributo ("La afirmación de Pedro es verdad"), mientras que las cláusulas de identidad incluyen en el predicado una expresión definida ("La afirmación de Pedro es la respuesta correcta") (Halliday y Matthiessen, 2004, pp. 219-220). Así pues, la cláusula relacional "Es verdad que $p$ " lleva a cabo una atribución de la cualidad de verdad al estado de cosas representado por un contenido proposicional; la cláusula relacional "La verdad es que $p$ ” consiste en una operación de identificación en que se codifica un valor identificador en una instancia identificada, concretamente en el estado de cosas representado por un contenido proposicional; finalmente, la cláusula relacional "Esto es verdad" constituye una atribución de la cualidad de verdad a una instancia pronominalmente indicada.
La expresión de verdad del primer ejemplo ("La verdad es que $p$ ") representa la identificación de una afirmación verdadera contenida en la cláusula incrustada del predicado (la oración subordinada sustantiva en función de atributo), y la noción de verdad aparece como sujeto, especificada deícticamente por el artículo determinante. Por otra parte, la expresión "La verdad es que" establece cierta propuesta de intercambio conversacional o posicionamiento argumentativo, en virtud del cual se introduce una respuesta reforzada, que contrasta con los enunciados previos; no en vano, en un 10,84\% de los casos registrados en el CREA (Real Academia Española, 2016 b), encontramos la expresión "pero la verdad es que", en que el juicio de verdad es antecedido por un conector adversativo, como se aprecia en el siguiente ejemplo:

(8) Dices que quieres volver, pero la verdad es que no sabes lo que quieres. (Pombo, citado por Real

Academia Española, 2016b)

Además, este ejemplo introduce una organización informativa que presenta como presupuesto temático la verdad de lo que se enuncia a continuación en tanto que información nueva.

En el segundo ejemplo ("Es verdad que $p$ ”), el juicio atribuye ideacionalmente la verdad a una cláusula incrustada como sujeto oracional (una oración subordinada sustantiva). En este caso, el patrón de significación interpersonal consiste en una propuesta argumentativa de concesión de ciertos presupuestos discursivos, que pueden aparecer denegados a continuación mediante una oración adversativa. Este sentido concesivo del juicio de verdad puede aparecer marcado por algún conector textual: hasta en un 17,14\% de los casos recogidos en el CREA, encontramos la expresión de refuerzo de cierta pretensión de validez "también es verdad que" o "bien es verdad que"; en un 8,02 \% de casos, aparecen las expresiones concesivas "si bien es verdad que" o "aunque es verdad que; en un 6,19\% de los casos, se da la expresión condicional "si es verdad que”. He aquí algunos ejemplos de estas expresiones: 
(9) La llegada del Partido Popular al gobierno, contrariamente a lo que esperábamos, no significó para la compañía inconveniente alguno. También es verdad que el nivel de intervención pública en nuestra actividad es relativamente bajo; pero se había amenazado con una preocupante entrada de los nacionales en el mundo cultural, una amenaza que después demostró ser una simple estratagema de la oposición. (Boadella, citado por Real Academia Española, 2016b)

(10) En el despacho del tío Enrique hay una biblioteca. Una auténtica biblioteca de libros encuadernados. Bien es verdad que los libros son de la colección Austral, pero dado que lo importante es la encuadernación, siendo esta la parte externa y visible del adminículo, ¿por qué bendita razón tendría que haber gastado más en el relleno? (Azúa, citado por Real Academia Española, 2016b)

(11) Una actividad de muy reciente aparición, es la joyería que produce aretes, pulseras, collares y otras piezas para el adorno personal. Si bien es verdad que la joyería prehispánica fue rica en variedad, no parece que en la de Santa Clara se haya logrado una buena integración. (Martínez Peñaloza, citado por Real Academia Española, 2016b)

(12) Pedro Camacho no parecía capaz de perder su tiempo, su energía, en la amistad ni en nada que lo distrajera de "su arte", es decir su trabajo o vicio, esa urgencia que barría hombres, cosas, apetitos. Aunque es verdad que a mí me toleraba más que a otros. (Vargas Llosa, citado por Real Academia Española, 2016b)

(13) Si al acto de quemar una bandera se le quitase el carácter de delito, quedaría privado de tal modo de sentido y aliciente, que a nadie se le pasaría por las mientes tomarse la molestia y aceptar el dispendio de ir a la pañería y soltar cuarenta duros por dos metros de tela rojigualda por el vano o dudoso placer de quemarlos en la plaza. $\underline{\text { Si es verdad que las leyes penalizan un acto para }}$ evitar que se cometa, he aquí un acto con respecto al cual la impunidad o la despenalización sería mucho más definitivamente disuasoria que la pena. (Sánchez Ferlosio, citado por Real Academia Española, 2016b)
Respecto al formato de organización informativa del ejemplo "Es verdad que $p$ ", se establece como marco temático dado la verdad de la proposición representada en la cláusula que figura como información nueva.

Por último, el tercer ejemplo ("Esto es verdad") también representa la relación lógica que atribuye la verdad a un contenido proposicional; pero en este caso cobra especial relevancia el significado textual aportado por la expresión, en la medida en que el pronombre remite endofóricamente al discurso previo y recapitula la coherencia de lo enunciado, validando su contenido. En cuanto a la organización informativa de la expresión "Esto es verdad", la verdad atribuida como predicado se aporta como información nueva y confirmación del discurso previamente dado. La propuesta interpersonal expresada en el ejemplo "Esto es verdad" consiste en la confirmación argumentativa de lo dicho anteriormente; en algunos casos, la expresión figura en la prótasis de una oración condicional, y el juicio de verdad adquiere un sentido contrafáctico, como se aprecia en el siguiente ejemplo:

(14) Una amiga me dijo que mi abuela solo tenía una historia y que por eso se repetía tanto. $\underline{\mathrm{Si}}$ eso es verdad, yo supero a la abuela en historias porque como mínimo tengo dos: la del billete que voló (a la que tal vez se parecen mucho el resto de historias que hasta ahora he inventado) y la de este fin de semana de Cerler. (Vila-Matas, citado por Real Academia Española, 2016b)

Los juicios de verdad del lenguaje cotidiano no siempre se comportan del mismo modo frente a la negación y, en ese sentido, se alejarían de las condiciones de verdad que rigen en un metalenguaje lógico formalizado. En los juicios de verdad que la lógica concibe bajo el ideal de un metalenguaje formalizable, existe cierta equivalencia entre la negación de un juicio de verdad y la falsedad de la proposición contenida en el juicio; por ejemplo, "No es verdad que $p$ " equivale lógicamente a "No $p$ ". Sin embargo, solo los juicios cotidianos del tipo "Es verdad que $p$ " exhiben cierta simetría lógica entre la negación externa del juicio de verdad y la negación interna de 
la proposición contenida en el juicio: "No es verdad que $p$ " equivale lógicamente a "Es verdad que no $p$ " (respecto a la negación externa e interna, véase Real Academia Española, 2010, p. 926). Sin embargo, no hay que dejarse engañar por la simple equivalencia lógica y representacional entre "No es verdad que $p$ " y "Es verdad que no $p$ ", ya que cada una de las expresiones realiza una propuesta interpersonal distinta: en el primer caso, se trata de refutar las expectativas de validez formuladas en algún enunciado previo o proposición discursiva supuesta; en el caso de "Es verdad que no $p$ ", se reproduce la pauta de significación interpersonal de "Es verdad que $p$ ", y estaríamos ante una propuesta argumentativa de concesión de ciertos supuestos discursivos. Los siguientes ejemplos ponen de manifiesto esta diferencia en el comportamiento de los juicios de verdad cotidianos:

(15) Él la dejaría colmada y llena. Sí, él la saciaría, como ningún otro lo había hecho. No es verdad que no hay que exigir nada para obtenerlo todo. No es verdad que, en la merced de ser elegida, consiste el único pago. No es verdad que la intensidad de una pasión basta para hacerla comunicable y compartible. No es verdad, tampoco, que un alto sentimiento sea un don tan preciado que dé derecho a ser correspondido. Estaba harta de equivocarse. (Rossetti, citado por Real Academia Española, 2016b)

(16) Me fui simplemente porque quería irme, me ahogaba su presencia. Me había cansado pero no es verdad que no le quisiera: necesitaba volar y me sentía atada a su respiración. (Cebrián, citado por Real Academia Española, 2016b)

(17) Ya hemos visto en el apartado anterior cómo los niños de cuatro años pertenecientes a esta capa asimilan como fenómeno próximo la presencia del trabajo. Bien es verdad que no se trata del trabajo libremente decidido, sino del medio que posibilita la supervivencia. La prole se dedica muy pronto a tareas productivas para aliviar así la carga familiar. Debido a esto, las diferencias entre los roles desempeñados por padres e hijos acaban por ser mínimas. (Caparrós, citado por Real Academia Española, 2016b)
Como puede apreciarse, en (15) y (16) se da la negación del juicio de verdad (e, incluso, la negación externa del juicio y la negación del contenido proposicional), como denegación de ciertos presupuestos discursivos; en (17), se da la negación interna del contenido proposicional, y el juicio de verdad significa interpersonalmente de modo análogo a los juicios del tipo "Es verdad que $p$ ", esto es, como una concesión argumentativa.

Por otra parte, los juicios cotidianos de verdad del tipo "La verdad es que $p$ " no permiten la negación externa del juicio de verdad ("La verdad no es que $p$ ”), sino solamente la negación interna del contenido proposicional ("La verdad es que no $p$ "). Esta asimetría quizá se debe a la gramaticalización de la expresión que introduce el juicio ("La verdad es que"), la cual opera como un marcador evidencial de compromiso subjetivo con la información del enunciado. Como se observa en el siguiente ejemplo, la negación del contenido proposicional del juicio de verdad no afecta al significado interpersonal de refuerzo evidencial:

(18) Lo cierto es que el dogmatismo político de aquellas gentes era tan rotundo, que llegué a pensar seriamente que el tío Rodolfo vivía equivocado y que la razón estaba de parte de los Moraldo, de los Repecho, de los Sobrado, de los Cabeza de Moro... de todos los que pululaban por el golf. Pero la verdad es que no conseguía formarme una idea muy clara de ningún partido político. (Salisachs, citado por Real Academia Española, 2016b)

En el caso de las expresiones cotidianas del tipo "Esto/Eso es verdad", solo cabe esperar la negación externa del juicio, pues el contenido proposicional únicamente aparece indicado pronominalmente en la instancia de discurso. La propuesta de significado interpersonal de un juicio como "Esto/Eso no es verdad" consiste generalmente en la refutación argumentativa de alguna proposición previamente expuesta o en la denegación dialógica de la intervención anterior de algún otro interlocutor, como se aprecia en los siguientes ejemplos:

(19) Un mito nefasto es el de suponer que la desaparición de los síntomas externos de una 
enfermedad de transmisión sexual, como la sífilis o la gonorrea, es señal de que está curada. Salvo casos más bien raros, esto no es verdad: la enfermedad sigue desarrollándose aun cuando no aparezcan síntomas externos, y sus consecuencias a medio plazo pueden ser muy negativas. (Ochoa, citado por Real Academia Española, 2016b)

(20) -Es que tú a veces me tratas como si tú no me quisieras - dijo ella al cabo de un momento, hipando todavía. - Eso no es verdad, eso no es verdad. (Vergés, citado por Real Academia Española, 2016b)

Ciertamente, las expresiones de juicios de verdad que se han ejemplificado no resultan tan frecuentes como algunas construcciones fraseológicas o como algunos marcadores discursivos del español; sin embargo, aparecen más a menudo que las instancias de definición formal de la verdad propuestas por los lógicos, de las cuales no hay un solo caso en todo el CREA. En ese sentido, la expresión "la verdad es que $p$ " se encuentra en el CREA con una frecuencia de 31,44 casos por cada millón de palabras; la expresión "es verdad que $p$ " aparece con una frecuencia de 15,27 casos por cada millón de palabras; la expresión "esto/eso es verdad" solo figura con una frecuencia de 1,89 casos por cada millón de palabras. Por cierto, cuando se revisan los casos de estas expresiones de juicios de verdad en el Corpus Diacrónico del Español (Real Academia Española, 2016a), llaman la atención las diferencias en la frecuencia relativa por siglo. Como se aprecia en la figura 1, las expresiones con un sentido concesivo o de refuerzo argumentativo ("es verdad que $p$ ") son las más frecuentes en todos los periodos analizados, y aumentaron su presencia relativa tendencialmente hasta el siglo XVIII, para luego exhibir un leve retroceso; las expresiones con un sentido de afirmación reforzada o adversativa ("la verdad es que $p$ ") han alcanzado cierta presencia en el conjunto de los juicios de verdad a contar del siglo XIX; por último, las expresiones pronominales de verdad ("esto/eso es verdad") han ido disminuyendo su frecuencia relativa desde el siglo xv. Cabría pensar, pues, que la verdad se dice de distintas maneras en diferentes épocas, y que la gramática de los juicios de verdad ha experimentado variaciones históricas.

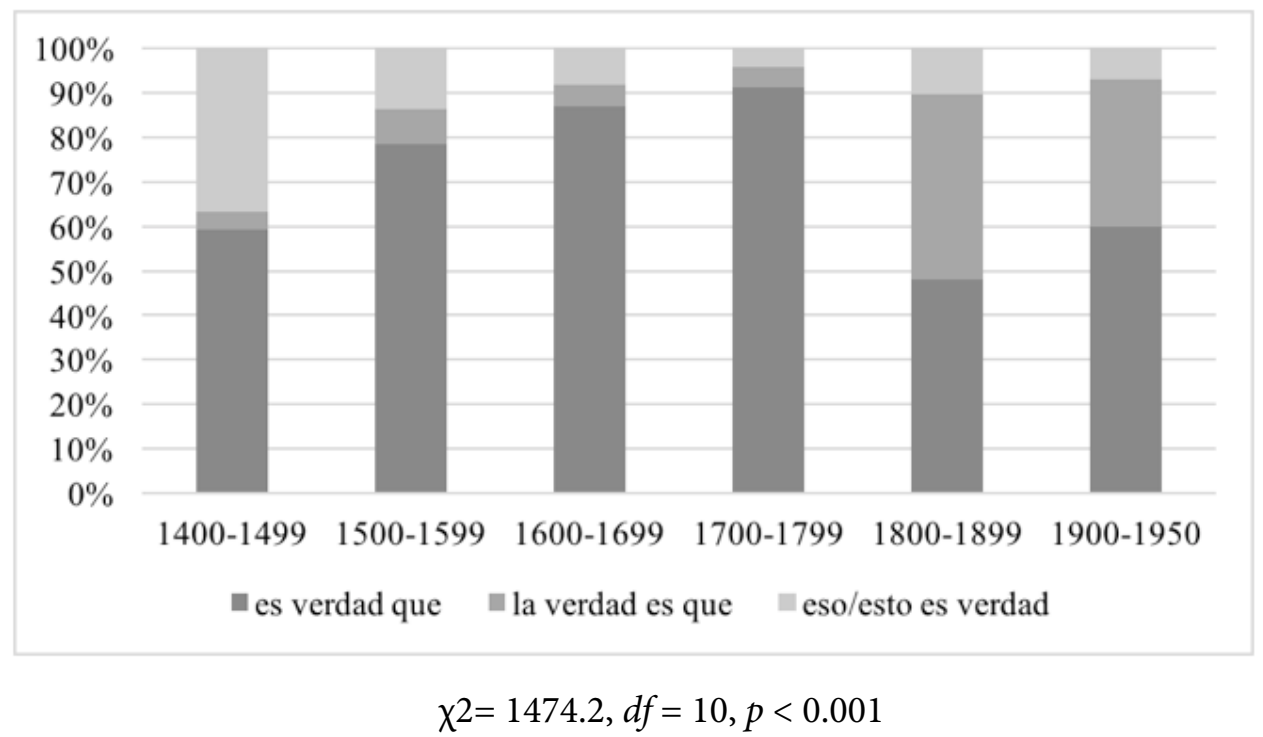

Figura 1. Frecuencia relativa de empleo de cada expresión de juicio de verdad en el CORDE, sobre el total de las expresiones consideradas ("es verdad que p", "la verdad es que p", "esto/eso es verdad"). 
Resumiendo, a diferencia de una regla formal de definición metalingüística de la verdad de contenidos proposicionales aislados, los diferentes juicios de verdad del lenguaje natural cotidiano constituyen actos discursivos distintos (de identificación o de atribución) y realizan movimientos retóricos diferentes en el curso del intercambio comunicativo (formulación de reservas y refuerzos argumentativos de contenidos proposicionales discretos, o bien confirmación de segmentos de discurso). En todos estos juicios de verdad expresados en el lenguaje natural, la atribución o identificación de la verdad surgen como una iniciativa o respuesta discursiva en el proceso de la comunicación interpersonal y del flujo textual, y no se reducen a una operación formal aislada sobre contenidos proposicionales libres de contexto. En las expresiones del tipo "es verdad que $p$ ", la verdad se predica como la condición de validez presunta atribuida al contenido proposicional de la oración incrustada en el sujeto; además, el juicio de verdad introduce un movimiento discursivo de concesión argumentativa, que suele dar paso a una corrección adversativa del contenido proposicional cuya verdad se concedió. En las expresiones del tipo "la verdad es que $p$ ", la verdad se dice como un valor identificado y determinado, que se instancia en el contenido proposicional de la oración incrustada en el predicado; el juicio de verdad introduce un movimiento argumentativo de corrección de los supuestos introducidos en el discurso. En las expresiones del tipo "esto/eso es la verdad", la verdad se predica como una propiedad o atributo genérico de una instancia pronominalmente indicada como sujeto; el movimiento retórico de este tipo de juicio de verdad consiste en un refuerzo confirmatorio de lo dicho previamente en el discurso. En la tabla 1 , se establecen las características distintivas de los juicios de verdad analizados.

Tabla 1. Comparación de los juicios de verdad expresados en el lenguaje natural

\begin{tabular}{|l|l|l|l|}
\hline & \multicolumn{1}{|c|}{ La verdad es que $\mathbf{p}$} & \multicolumn{1}{c|}{ Es verdad que $\mathbf{p}$} & Esto/Eso es verdad \\
\hline Tipo de cláusula relacional & identificación & atribución & atribución \\
\hline Movimiento retórico & corrección & concesión & confirmación \\
\hline Contenido del juicio & contenido proposicional & contenido proposicional & instancia pronominal \\
\hline $\begin{array}{l}\text { Realización gramatical } \\
\text { del término verdad }\end{array}$ & sujeto definido, tema supuesto & $\begin{array}{l}\text { predicado indefinido, } \\
\text { tema supuesto }\end{array}$ & $\begin{array}{l}\text { predicado indefinido, } \\
\text { información nueva }\end{array}$ \\
\hline Ámbito de la posible negación & $\begin{array}{l}\text { interno (del contenido } \\
\text { proposicional) }\end{array}$ & externo e interno & externol juicio de verdad) \\
\hline
\end{tabular}

Fuente: elaboración propia.

\section{Rendimientos metalingüísticos, metadiscursivos y metacomunicativos de los juicios cotidianos de verdad}

Ciertamente, el lenguaje natural cuenta con los recursos semióticos para realizar juicios de verdad, sin que sea necesario un metalenguaje formalmente escindido. Por otra parte, los juicios de verdad formulados en el lenguaje natural exhiben notables rendimientos metalingüísticos y metadiscursivos. En los estudios sobre el metalenguaje en español, se ha considerado que existe todo un repertorio léxico metalingüístico y un conjunto de marcadores metadiscursivos que hacen posible operar reflexivamente con el lenguaje cotidiano (Loureda, 2009, pp. 324-328). En el léxico no terminológico hallamos todo un vocabulario con un contenido metalingüístico, que permite que los hablantes formulen juicios valorativos de los discursos; concretamente, términos como verdadero, exacto, preciso, etc., hacen posible la evaluación del estatuto de los enunciados en relación con la finalidad lógica y apofántica del discurso (Casado, 2001, p. 3). Por otra parte, entre los marcadores discursivos que funcionan como modalizadores de la enunciación, se hacen presentes 
algunos marcadores metadiscursivos al servicio de la atenuación o intensificación tanto del decir como de lo dicho; por ejemplo, "verdaderamente", "a decir verdad", o bien "la verdad sea dicha", cumplen una función metadiscursiva o metapragmática, en la medida en que marcan la posición del enunciador ante lo que dice, y enmarcan las expectativas intersubjetivas de validez (González y Loureda, 2005, p. 362). En los estudios sobre el metalenguaje en español, se ha establecido que estos modalizadores metadiscursivos ("la verdad", "a decir verdad", "la verdad sea dicha", "verdaderamente") responden al principio de cooperación comunicativa $y$, concretamente, explicitan cierta máxima conversacional, esto es, la expectativa normativa de que no se enuncie nada falso o para lo cual no se disponga de pruebas (Aznárez, González, Manero y Loureda, 2002, p. 24). Como se desprende de estos análisis del metalenguaje en español, el lenguaje natural cuenta con el potencial semiótico para juzgar la validez de los enunciados del discurso, así como para dar cuenta de la modalidad de la enunciación y articular las pretensiones discursivas de validez. Ahora bien, esta capacidad del lenguaje natural para volverse reflexivamente sobre sí mismo y orientar estratégicamente el proceso de la comunicación no requiere de un código metalingüístico acotado o de un metalenguaje formalizado de orden superior; simplemente, resulta consustancial al sistema de significación de la lengua cotidiana. De hecho, no solo resulta complicado trazar una posible línea divisoria entre los recursos semióticos del lenguaje y sus rendimientos metalingüísticos, sino que, además, podría discutirse en qué medida pueden separarse los usos metalingüísticos y las funciones metadiscursivas o metacomunicativas de algunas expresiones. Es lo que ocurre en el caso de los juicios de verdad con la estructura "La verdad es que $p$ ", "Es verdad que p" o "Esto/Eso es verdad".

Al examinar los juicios de verdad expresados en el lenguaje cotidiano ("La verdad es que $p$ ", "Es verdad que $p$ " o "Esto/Eso es verdad"), se pone de manifiesto que el español dispone de un término con un marcado sentido metalingüístico, el léxico de la verdad, que significa la adecuación o correspondencia entre nuestras representaciones o proposiciones, y por otra parte, los estados de cosas o hechos referidos. Se trata de un elemento lingüístico o recurso léxico que puede significar la propia relación del lenguaje con lo designado, el nexo entre el decir y lo dicho. Ahora bien, la condición metalingüística del léxico de la verdad no se reduce a la semántica del término, capaz de representar una relación representacional; además, concierne a la realización gramatical de los juicios de verdad. En los juicios de verdad del lenguaje natural ("La verdad es que $p$ ", "Es verdad que $p$ " o "Esto/Eso es verdad"), el sustantivo verdad se perfila como una instancia metalingüística oracional, en la medida en que el nombre se refiere al estatuto de la cláusula como un mensaje dentro del texto, más que referir entidades concretas o estados de cosas del mundo externo. Como ha argumentado Eugene Winter (1992, pp. 132-134), existen nombres metalingüísticos (como idea, problema, respuesta, etc.), que tienen la particularidad de exhibir una referencia endofórica a otros elementos textuales, de manera que este tipo de términos relaciona gramaticalmente los elementos textuales y establece cómo han de entenderse las palabras. En concreto, estos nombres metalingüísticos se caracterizan por resultar intrínsecamente inespecíficos, pero asumen la función de enmarcar la interpretación de las cláusulas que especifican su significado dentro del texto. En ese sentido, un nombre como idea especifica su significado dentro de algún sintagma u oración textual, de modo que orienta las interpretaciones del mensaje. Según Winter, este efecto de especificación de los nombres metalingüísticos se lleva a cabo cuando el término es identificado por medio de modificadores, o bien mediante una cláusula. Por ejemplo, el nombre metalingüístico idea puede especificar su contenido con algún sintagma preposicional en función de modificador, como ocurre en las expresiones "la idea de acabar con el desempleo", o bien "la idea de que la crisis económica se profundiza”; asimismo, 
cabe especificar el contenido del término con una frase o cláusula, como es el caso en la oración "La idea es que viajemos pronto". Algunos nombres metalingüísticos (como consecuencias o resultados) especifican su contenido al referir a varias frases precedentes $\mathrm{u}$ oraciones de un texto, de manera que se refuerza su funcionamiento metalingüístico, mediante la alusión a relaciones textuales supraoracionales (Winter, 1992, p. 134).

Pues bien, cabría considerar que el sustantivo verdad presente en los juicios de verdad del lenguaje cotidiano constituye un caso de léxico metalingüístico: se trata de un término de significado inespecífico, que enmarca la interpretación del segmento textual en que se especifica su significado; concretamente, verdad sería un nombre metalingüístico cuyo contenido se torna específico en la cláusula del juicio de verdad ("La verdad es que $p$ ", "Es verdad que $p$ ") e, incluso, mediante la referencia endofórica a secuencias textuales previas, que proveen el contenido del término (como ocurre especialmente en el juicio "Esto/Eso es verdad").

Aunque los términos referencialmente inespecíficos como verdad tienen notables rendimientos metalingüísticos, quizá no resulte preciso caracterizarlos como un repertorio léxico acotado de nombres metalingüísticos. Hans-Jörg Schmid (2000; 2001) emplea el concepto de nombres caparazón o nombres cápsula (shell nouns), para designar a cierto tipo de nombres abstractos, referencialmente inespecíficos, que enmarcan conceptualmente enunciados y conjuntos de información, de manera que activan cierta interpretación del mensaje, generan vínculos textuales y modelan la experiencia bajo la forma de configuraciones conceptuales integradas. Desde la perspectiva gramatical, los nombres cápsula o caparazón figuran en construcciones del tipo "El $N$ de que $p$ ", o bien "El $N$ es que $p$ " (por ejemplo, "La idea de que el gobierno aumente los impuestos", "El hecho de que la policía tiene problemas de corrupción", o bien "La cosa es que no hay avances en educación"). Según Schmid, existen distintos tipos de nombres caparazón o cápsula que pueden aparecer en construcciones relacionales con la forma "El $N$ es que $p$ ": términos factuales ( $\cos a$, punto, problema, resultado, etc.); términos lingüísticos alusivos a contenidos proposicionales o de carácter ilocucionario (argumento, cuento, respuesta, sugerencia, etc.); términos mentales relacionados con creencias o emociones (idea, teoría, impresión, preocupación, temor, etc.); o conceptos modales o evidenciales (posibilidad, riesgo, hecho, realidad, verdad, etc.) (Schmid, 2001, p. 1532).

Estos nombres caparazón encapsulan conjuntos de información y segmentos de discurso, en la medida en que presentan un hueco o indefinición referencial en su estructura semántica, y operan como etiquetas del contenido proposicional y enunciativo que cobijan. En ese sentido, estos caparazones conceptuales no solo dan cobertura a cierta interpretación del mensaje, sino que, además, contribuyen a reificar el contenido de los enunciados e hipostasiar la configuración conceptual, como si se tratase de totalidades autosubsistentes (Schmid, 1997). Según Schmid (2000; 2001), los nombres cápsula o caparazón contribuyen a la cohesión textual (pues establecen relaciones entre segmentos textuales) y a la organización informativa (ya que marcan la información conocida o tema y la información nueva, así como focalizan la información relevante). Además, estos términos caparazón tienen importantes rendimientos metadiscursivos, al permitir el posicionamiento discursivo, orientar las expectativas de sentido y contribuir a la negociación del significado; desempeñan, según Schmid (2001, pp. 1531-1532), una función metacomunicativa, al suministrar indicaciones para la interpretación del contenido de los mensajes. En ese sentido, los nombres caparazón o cápsula desencadenan presuposiciones semánticas y pragmáticas que enmarcan las expectativas interpretativas y las asunciones discursivas; eventualmente, pueden convertirse en un señuelo o trampantojo con un potencial manipulador para moldear el estatuto epistémico de los mensajes y las pretensiones de validez (Schmid, 2001, pp. 1544-1546).

El riesgo de manipulación de las expectativas interpretativas y los marcos discursivos se plantea 
en los juicios de verdad del lenguaje cotidiano: el término verdad constituye un nombre cápsula modal o caparazón conceptual evidencial que, particularmente en los enunciados de la forma " $\mathrm{La}$ verdad es que $p$ ", parece blindar las pretensiones discursivas de validez de del contenido proposicional al que da cobertura. En todo caso, los juicios de verdad del tipo "Es verdad que $p$ " plantean un escenario conceptual más complejo, ya que generalmente introducen el contenido proposicional como una concesión de la cual el discurso se desmarca posteriormente. Respecto a los juicios de verdad del tipo "Esto/Eso es verdad", el efecto de encapsulamiento tiene marcados rendimientos metadiscursivos, al asociarse a la vinculación de contenidos textuales y a la recapitulación discursiva. En los tres tipos de juicio de verdad, el término caparazón verdad resulta decisivo para la organización informativa, tanto al distribuir los temas conocidos y la información nueva como al situar cierta información en el foco. Concretamente, en los juicios del tipo "La verdad es que $p$ " o " $E s$ verdad que $p$ ", se marca como información supuesta o tema cierta pretensión de validez, y figura como información nueva el contenido proposicional del enunciado, que aparece como foco de información evidente; en el caso de "Esto/Eso es verdad", la pretensión de validez expresada en el término caparazón verdad figura como información nueva, mientras se asume como supuesto el conjunto de enunciados textuales indicados endofóricamente por el pronombre. En todo caso, los juicios de verdad del lenguaje natural pueden analizarse como cierto tipo de realización léxico-gramatical con rendimientos informativos, metadiscursivos y metacomunicativos cotidianos (que pueden incluir la reificación e hipostatización del contenido discursivo y del marco conceptual), sin necesidad de postular un metalenguaje formalmente escindido de orden superior.

Cierto análisis posible de los juicios de verdad del lenguaje cotidiano se centra en el léxico metalingüístico (concretamente, en el término cápsula evidencial verdad), que aportaría un enmarcado discursivo y conceptual del contenido proposicional con el cual se vincula en cláusulas relacionales.
Ahora bien, algunos juicios de verdad del lenguaje natural (específicamente, de las construcciones "La verdad es que $p$ ", "Es verdad que $p$ ") podrían analizarse como enunciados en que se hacen presentes marcadores (meta)discursivos ("la verdad", "la verdad es que", "es verdad", o bien "es verdad que"). Este tipo de marcadores (meta)discursivos consistiría en construcciones convencionales que no añaden información al enunciado y cuyo significado léxico pasa a segundo plano, pero que enmarcan la enunciación, los posicionamientos discursivos y los modos de negociación de los significados en el curso de la interacción comunicativa. Al abordar algunos marcadores discursivos del español, María José Serrano (1997) ha propuesto un análisis de la construcción "la verdad es que" en que se considera dicha expresión como un marcador pragmático, análogo al sintagma "la verdad". Según Serrano (1997, pp. 266-267), los marcadores discursivos contribuyen a la estructuración coherente del discurso, al integrar el significado de los enunciados y el propósito de la enunciación; además, contribuyen a la cohesión textual, ya que distribuyen las unidades de enunciación y relacionan los enunciados; por último, enmarcan la interacción comunicativa y suministran indicaciones para la comprensión recíproca. Como se puede apreciar, la caracterización de los marcadores discursivos da cuenta de su función metadiscursiva inherente. En el caso del marcador metadiscursivo "la verdad", Serrano (1997, p. 269) argumenta que se trata de una indicación pragmática del contenido asertivo del enunciado en que aparece la expresión, como si el sintagma introdujese y actualizase un acto de habla de aserción.

En ese sentido, cabe distinguir dos contextos en que figura como marcador (meta)discursivo "la verdad": la expresión puede aparecer como introductor de una respuesta, en construcciones con la forma " $\mathrm{La}$ verdad es que $p$ "; el marcador discursivo la verdad también se encuentra frecuentemente en aposición, entre comas, inserta en un enunciado cuyo mensaje apoya o refuerza (por ejemplo, "A mí, la verdad, no me gusta bailar"). En ambos usos de la expresión "la verdad" como marcador pragmático, se introduce 
un marco de cohesión y coherencia discursiva centrado en el acto asertivo; además, la actualización del enunciado como aserción incorpora cierto componente expresivo, específicamente un posicionamiento ante la cuestión en discusión, cuando se trata del marcador que introduce una respuesta (" $\mathrm{La}$ verdad es que $p$ ”) o bien ante el enunciado, cuando se refuerza el contenido proposicional (“ $p$, la verdad”). En "La verdad es que $p$ " se remarca la validez o credibilidad epistémica de la posición discursiva introducida, específicamente si se marca distancia con la pregunta o si el enunciado contraviene las expectativas discursivas; por otra parte, en el marcador de apoyo (“ $p$, la verdad") simplemente se mantiene la coherencia asertiva de la información contenida en el enunciado (Serrano, 1997, pp. 270-272). Desde una perspectiva sociolingüística, Serrano sostiene que el marcador discursivo introductor de una respuesta divergente ("la verdad es que") podría asociarse a un posicionamiento discursivo indirecto y a un comportamiento sociocomunicativo abierto a la negociación, que atenúa parcialmente el compromiso con lo enunciado; sobre todo, cuando hay distancia social o diferencia de estatus. Por el contrario, el marcador discursivo de refuerzo del mensaje o apoyo a la información (" $p$, la verdad") se vincula a comportamientos sociocomunicativos más tajantes, seguros, convencidos y conclusivos, frecuentemente vinculados a niveles socioculturales elevados (Serrano, 1997, pp. 272-276).

Al parecer, existen dos aproximaciones gramaticales para dar cuenta de juicios de verdad cotidianos del tipo "La verdad es que $p$ ": se puede analizar ese tipo de construcciones como cláusulas relacionales encapsuladas por un término caparazón, que enmarca el sentido del enunciado (por analogía con construcciones como "El hecho es que los delitos contra la propiedad se han incrementado"); pero también cabe analizar la expresión como un enunciado modalizado por un marcador (meta) discursivo evidencial (por analogía con construcciones como "No ha habido, la verdad, progresos en la economía del país", o bien "Verdaderamente, tiene un buen currículo"). El primer análisis se centra en las características léxicas del término verdad, en tanto que nombre metalingüístico, y reconstruye los rendimientos metadiscursivos de construcciones como "La verdad es que $p$ " a partir de los constituyentes léxico-gramaticales. El segundo análisis parte directamente de un segmento textual o sintagma ("la verdad" o "la verdad es que") como marcador pragmático (meta)discursivo que enmarca las expectativas interpretativas y coordina el proceso comunicativo. ¿Se pueden compatibilizar las dos formas de análisis? Serrano (1997, p. 270) plantea que el rendimiento asertivo del marcador pragmático "la verdad" se sostiene en el significado léxico de verdad, si bien parece intervenir cierta erosión léxica, en virtud de la cual la expresión adquiere un sentido primordialmente discursivo; se habría dado, pues, de un proceso de gramaticalización del segmento.

En ese sentido, podría argumentarse que los análisis léxico-gramatical y pragmático-discursivo de los juicios de verdad del tipo "La verdad es que $p$ " no resultan incompatibles, siempre y cuando introduzcamos algún mecanismo explicativo que dé cuenta de los rendimientos metadiscursivos de la expresión, a partir del particular estatuto de un nombre metalingüístico (o un término caparazón inespecífico) como verdad y de las construcciones encapsuladas cuyo contenido enmarca dicho sustantivo. La presencia de un proceso de gramaticalización hace posible explicar de qué manera el sintagma "la verdad" o la construcción "la verdad es que" han perdido parte de su significado léxico, para convertirse básicamente en operadores pragmáticos que enmarcan el enunciado, guían la interpretación y responden a posicionamientos subjetivos en la enunciación. Como mecanismo explicativo, la gramaticalización da cuenta precisamente del modo en que algunas expresiones dejan de asociarse a significados léxicos concretos (o bien a contenidos proposicionales objetivos), y pasan a asumir funciones pragmáticas ligadas a la expresión de las creencias y actitudes subjetivas; desde esa perspectiva, el proceso diacrónico de gramaticalización puede involucrar una marcada subjetivación discursiva (Traugott, 1995, p. 48). En gran medida, los juicios de verdad del lenguaje cotidiano corresponden a construcciones gramaticalizadas y convencionales, 
en las cuales se ha desgastado parcialmente el contenido léxico del término verdad. Sin embargo, ese proceso de debilitamiento léxico de un nombre con marcado talante metalingüístico (verdad) se ha traducido en una intensificación de los rendimientos metadiscursivos de construcciones como "La verdad es que" o "Es verdad que", a través de las cuales se deciden relaciones textuales, marcos interpretativos y expectativas intersubjetivas. En todo caso, los rendimientos metalingüísticos, metadiscursivos y metacomunicativos de los juicios de verdad formulados en el lenguaje cotidiano no dependen de la existencia de un código metalingüístico acotado o de un metalenguaje formalizado de orden superior. Hay toda una gramática cotidiana de la verdad, la cual se sirve del potencial semiótico del sistema de significación de la lengua natural, pero responde además a todo un proceso de gramaticalización y subjetivación discursiva de los juicios de verdad.

\section{Referencias}

Aznárez, M., González, R., Manero, E., y Loureda, L., O. (2002). Tres calas (más) en el metalenguaje del español. Anuario de Estudios Filológicos, 25, 17-33.

Casado, M. (2001). Semántica y pragmática en el léxico metalingüístico (metadiscursivo) del español actual. En J. Gutiérrez-Rexach (ed.), Meaning and the Components of Grammar (pp. 95-112). Múnich: LinCom Europa.

González, R., y Loureda Lamas, O. (2005). Algunos estudios recientes sobre lo metalingüístico en español. Verba, 32, 351-369.

González, R. (2006). De la lingüística intuitiva a la lingüística reflexiva: alcances y límites de la cultura lingüística implícita en la lengua española. En R. González R., M. Casado V. y M. A. Esparza T. (eds.), Discurso, lengua y metalenguaje. Balance y perspectivas (pp. 121-137). Hamburgo:Helmut Buske Verlag.

Gutiérrez, S. (1989). Del uso metalingüístico. Archivum, 37-38, 5-19.

Halliday, M. y Matthiessen, C.(2004). An Introduction to Functional Grammar, 3a. ed). Londres: Hodder Arnold.

Hernández, C. (1996). Procedimientos y mecanismos del metalenguaje en español. Lexis, 20(1-2), 373-392.
Hjelmslev, L. (1971). Prolegómenos a una teoría del lenguaje. Madrid: Gredos.

Hyland, K. (2005). Metadiscourse. Exploring Interaction in Writing. Londres: Continuum.

Jakobson, R. (1988). El metalenguaje como problema lingüístico. En El marco del lenguaje (pp. 81-91). México, D. F.: Fondo de Cultura Económica.

López, G. A. (1980). Para una gramática liminar. Madrid: Cátedra.

Loureda, O. (2009). De la función metalingüística al metalenguaje: Los estudios sobre el metalenguaje en la lingüística actual. Revista Signos, 42(71), 317-332.

Lucy, J. (1993). Reflexive language and the human disciplines. En J.A. Lucy (ed.), Reflexive language. Reported speech and metapragmatics (pp. 9-32). Cambridge: Cambridge University Press.

Lyons, J. (1997). Semántica lingüística. Barcelona: Paidós.

Martín, M. y Portolés , J. (1999). Los marcadores del discurso. En I. Bosque y V. Demonte (eds.), Gramática descriptiva de la lengua española, (Vol. 3, pp. 40514213). Madrid: Espasa-Calpe.

Nicolás, J., y Frápolli, M. (eds.). (1997). Teorías de la verdad en el siglo XX. Madrid: Tecnos.

Real Academia Española. (2010). Nueva gramática de la lengua española. Manual. Buenos Aires: Espasa.

Real Academia Española. (2016a). Corpus diacrónico del español (CORDE). [Banco de datos en línea]. Recuperado de http://www.rae.es

Real Academia Española. (2016b). Corpus de referencia del español actual (CREA). [Banco de datos en línea]. Recuperado de http://www.rae.es).

Schmid, H. (1997). Constant and ephemeral hypostatization: Thing, problem and other shell nouns. En B. Caron (ed.), Proceedings of the 16th International Congress of Linguists [CD-ROM]. Ámsterdam: Elsevier.

Schmid, H. (2000). English Abstract Nouns as Conceptual Shells. From Corpus to Cognition. Berlín: Mouton de Gruyter.

Schmid, H. (2001). Presupposition can be a bluff: How abstract nouns can be used as presupposition triggers. Journal of Pragmatics, 33, 1529-1552.

Serrano, M. (1997). Marcadores discursivos en español: acerca de la verdad y pues. Boletín de Filología de la Universidad de Chile, 36, 265-286.

Tarski, A. (2005). La concepción semántica de la verdad y los fundamentos de la semántica. En L. M. Valdés 
V. (ed.), La búsqueda del significado. Lecturas de filosofía del lenguaje. Cuarta edición (pp. 299-335). Madrid: Tecnos.

Traugott, E. (1995). Subjectification in grammaticalisation. En D. Stein y S. Wright (eds.), Subjectivity and Subjectivisation: Linguistic Perspectives (pp. 31-54). Nueva York: Cambridge University Press.

Vigara, A. (1992). Función metalingüística y uso del lenguaje. Epos, 8, 123-141
Weinrich, H. (1981). De la cotidianidad del metalenguaje. En Lenguaje en textos (pp. 110-139). Madrid: Gredos.

Winter, E.(1992). The Notion of Unspecific versus Specific as one Way of Analysing the Information of a FundRaising Letter. En W. C. Mann y S. A. Thompson (eds.), Discourse description: diverse linguistic analyses of a fund-raising text (pp. 131-170). Ámsterdam: John Benjamins Publishing.

Para citar este artículo

González de Requema, J. (2018). Metalenguaje y gramática de algunos juicios cotidianos de verdad en español. Folios, 48, 57-71. 